\title{
Stability of hepatitis B virus pregenomic RNA in plasma specimens under various temperatures and storage conditions
}

\author{
Pakkapon Rattanachaisit ${ }^{1,2}$, Sirinporn Suksawatamnuay ${ }^{3,4}$, Supachaya Sriphoosanaphan ${ }^{1,3}$, Kessarin Thanapirom \\ ${ }_{1,4}^{1,}$, Panarat Thaimai ${ }^{3,4}$, Nipaporn Siripon ${ }^{3,4}$, Sukanya Sittisomwong ${ }^{3,4}$, Yong Poovorawan ${ }^{5}$, Piyawat Komolmit ${ }^{\text {Corresp. }}$ \\ $1,3,4$ \\ ${ }^{1}$ Division of Gastroenterology, Department of Medicine, Faculty of Medicine, Chulalongkorn University and King Chulalongkorn Memorial Hospital, \\ Bangkok, Thailand \\ 2 Department of Physiology, Faculty of Medicine, Chulalongkorn University, Bangkok, Thailand \\ 3 Center of Excellence in Liver Diseases, King Chulalongkorn Memorial Hospital, Thai Red Cross Society, Bangkok, Thailand \\ 4 Liver Fibrosis and Cirrhosis Research Unit, Chulalongkorn University, Bangkok, Thailand \\ 5 Center of Excellence in Clinical Virology, Faculty of Medicine, Chulalongkorn University, Bangkok, Thailand \\ Corresponding Author: Piyawat Komolmit \\ Email address: pkomolmit@yahoo.co.uk
}

Background. Hepatitis B virus (HBV) pregenomic RNA (pgRNA) has gained increasing attention owing to its role in replication of covalently closed circular DNA (ccCDNA) in HBV. This marker has the potential to be used in clinical programs aimed to manage HBV infections. However, several reports on HBV pgRNA levels in clinical cases have conflicting results. RNA is easily degraded when exposed to heat and other environmental stressors. However, the stability of HBV pgRNA, during blood sample collection before the standard automated quantification, has never been estimated. This study aimed to demonstrate the effect of two different temperature conditions and storage durations on the stability of HBV pgRNA.

Method. Blood from forty patients with chronic hepatitis B infection, who also showed evidence of active HBV DNA replication, was collected and processed within $2 \mathrm{~h}$ of collection. Plasma from each patient was divided and stored at $4{ }^{\circ} \mathrm{C}$ and $25^{\circ} \mathrm{C}$ (room temperature) for six different storage durations $(0,2,6,12$, 24 , and $48 \mathrm{~h}$ ) and subsequently transferred to $-80^{\circ} \mathrm{C}$ for storage. The effect of multiple cycles of freezing and thawing of plasma at $-20^{\circ} \mathrm{C}$ or $-80{ }^{\circ} \mathrm{C}$ was evaluated using samples from ten patients. Quantification of pgRNA from the samples was performed simultaneously, using the digital polymerase chain reaction ( $d P C R$ ) method. The differences in pgRNA levels at baseline and each time point were compared using generalized estimating equation (GEE). A change greater than $0.5 \log _{10}$ copies/mL of pgRNA is considered clinically significant. Statistical analyses were conducted using Stata 16.0.

Results. The mean HBV pgRNA level in the initially collected plasma samples was $5.58 \log _{10}$ copies $/ \mathrm{mL}$ (ranging from 3.08 to $8.04 \log _{10}$ copies $/ \mathrm{mL}$ ). The mean pgRNA levels in samples stored for different time periods compared with the initial reference sample (time 0 ) significantly decreased. The levels of pgRNA for $6,12,24$, and $48 \mathrm{~h}$ of storage reduced by $-0.05 \log _{10}$ copies/mL (95\% confidence interval $(\mathrm{Cl})-0.095$ to $-0.005, p=0.03),-0.075 \log _{10}$ copies $/ \mathrm{mL}(95 \% \mathrm{Cl}-0.12$ to $-0.03, \mathrm{p}=0.001),-0.084 \log _{10}$ copies $/ \mathrm{mL}(95 \%$ $\mathrm{Cl}-0.13$ to $-0.039, \mathrm{p}=<0.001)$, and $-0.120 \log _{10} \mathrm{copies} / \mathrm{mL}(95 \% \mathrm{Cl}-0.17$ to $-0.076, \mathrm{p}=<0.001)$, respectively. However, these changes were below $0.5 \log _{10}$ copies/mL and thus were not clinically significant. Compared with the samples stored at $4{ }^{\circ} \mathrm{C}$, there were no significant differences in pgRNA levels in samples stored at $25^{\circ} \mathrm{C}$ for any of the storage durations $\left(-0.01 \log _{10}\right.$ copies $/ \mathrm{mL} ; 95 \% \mathrm{Cl}-0.708$ to $0.689, p=0.98)$. No significant difference in the levels of pgRNA was observed in the plasma samples, 
following four freeze-thaw cycles at $-20^{\circ} \mathrm{C}$ and $-80^{\circ} \mathrm{C}$.

Conclusion. The plasma HBV pgRNA level was stable at $4{ }^{\circ} \mathrm{C}$ and at room temperature for at least $48 \mathrm{~h}$ and under multiple freeze-thaw cycles. Our results suggest that pgRNA is stable during the process of blood collection, and therefore, results of pgRNA quantification are reliable. 


\section{Stability of hepatitis B virus pregenomic RNA in}

2 plasma specimens under various temperatures and

3 storage conditions

4

5 Pakkapon Rattanachaisit ${ }^{1,2}$, Sirinporn Suksawatamnuay ${ }^{3,4}$, Supachaya Sriphoosanaphan ${ }^{1,3}$,

6 Kessarin Thanapirom ${ }^{1,4}$, Panarat Thaimai ${ }^{3,4}$, Nipaporn Siripon ${ }^{3,4}$, Sukanya Sittisomwong ${ }^{3,4}$, Yong

7 Poovorawan ${ }^{5}$, Piyawat Komolmit ${ }^{1,3,4}$

${ }^{1}$ Division of Gastroenterology, Department of Medicine, Faculty of Medicine, Chulalongkorn University and King Chulalongkorn Memorial Hospital, Bangkok, Thailand

${ }^{2}$ Department of Physiology, Faculty of Medicine, Chulalongkorn University, Bangkok, Thailand

${ }^{3}$ Center of Excellence in Liver Diseases, King Chulalongkorn Memorial Hospital, Thai Red Cross Society, Bangkok, Thailand

${ }^{4}$ Liver Fibrosis and Cirrhosis Research Unit, Chulalongkorn University, Bangkok, Thailand

${ }^{5}$ Center of Excellence in Clinical Virology, Faculty of Medicine, Chulalongkorn University, Bangkok, Thailand

Corresponding Author:

Piyawat Komolmit ${ }^{1}$

Division of Gastroenterology, Department of Medicine, Faculty of Medicine, Chulalongkorn University and King Chulalongkorn Memorial Hospital, Bangkok, 10330, Thailand

Email address: pkomolmit@yahoo.co.uk

\footnotetext{
Abstract

Background. Hepatitis B virus (HBV) pregenomic RNA (pgRNA) has gained increasing attention owing to its role in replication of covalently closed circular DNA (cccDNA) in HBV. This marker has the potential to be used in clinical programs aimed to manage HBV infections. However, several reports on HBV pgRNA levels in clinical cases have conflicting results. RNA is easily degraded when exposed to heat and other environmental stressors. However, the stability of HBV pgRNA, during blood sample collection before the standard automated
} 
31 quantification, has never been estimated. This study aimed to demonstrate the effect of two

32

33

34

35

36

37

38

39

40

different temperature conditions and storage durations on the stability of HBV pgRNA.

Method. Blood from forty patients with chronic hepatitis B infection, who also showed evidence of active HBV DNA replication, was collected and processed within $2 \mathrm{~h}$ of collection. Plasma from each patient was divided and stored at $4{ }^{\circ} \mathrm{C}$ and $25^{\circ} \mathrm{C}$ (room temperature) for six different storage durations $(0,2,6,12,24$, and $48 \mathrm{~h})$ and subsequently transferred to $-80^{\circ} \mathrm{C}$ for storage. The effect of multiple cycles of freezing and thawing of plasma at $-20^{\circ} \mathrm{C}$ or $-80^{\circ} \mathrm{C}$ was evaluated using samples from ten patients. Quantification of pgRNA from the samples was performed simultaneously, using the digital polymerase chain reaction (dPCR) method. The differences in pgRNA levels at baseline and each time point were compared using generalized estimating equation (GEE). A change greater than $0.5 \log _{10}$ copies $/ \mathrm{mL}$ of pgRNA is considered clinically significant. Statistical analyses were conducted using Stata 16.0.

Results. The mean HBV pgRNA level in the initially collected plasma samples was $5.58 \log _{10}$ copies $/ \mathrm{mL}$ (ranging from 3.08 to $8.04 \log _{10}$ copies $/ \mathrm{mL}$ ). The mean pgRNA levels in samples stored for different time periods compared with the initial reference sample (time 0 ) significantly decreased. The levels of pgRNA for $6,12,24$, and $48 \mathrm{~h}$ of storage reduced by $-0.05 \log _{10}$ copies $/ \mathrm{mL}$ (95\% confidence interval (CI) -0.095 to $-0.005, \mathrm{p}=0.03),-0.075 \log _{10}$ copies $/ \mathrm{mL}$ ( $95 \% \mathrm{CI}-0.12$ to $-0.03, \mathrm{p}=0.001),-0.084 \log _{10}$ copies $/ \mathrm{mL}(95 \% \mathrm{CI}-0.13$ to $-0.039, \mathrm{p}=<0.001)$, and $-0.120 \log _{10}$ copies $/ \mathrm{mL}$ ( $95 \%$ CI -0.17 to $-0.076, \mathrm{p}=<0.001$ ), respectively. However, these changes were below $0.5 \log _{10}$ copies $/ \mathrm{mL}$ and thus were not clinically significant. Compared with the samples stored at $4{ }^{\circ} \mathrm{C}$, there were no significant differences in pgRNA levels in samples stored at $25^{\circ} \mathrm{C}$ for any of the storage durations $\left(-0.01 \log _{10}\right.$ copies $/ \mathrm{mL} ; 95 \% \mathrm{CI}-0.708$ to $0.689, \mathrm{p}$ $=0.98)$. No significant difference in the levels of pgRNA was observed in the plasma samples, following four freeze-thaw cycles at $-20{ }^{\circ} \mathrm{C}$ and $-80^{\circ} \mathrm{C}$.

Conclusion. The plasma HBV pgRNA level was stable at $4{ }^{\circ} \mathrm{C}$ and at room temperature for at least $48 \mathrm{~h}$ and under multiple freeze-thaw cycles. Our results suggest that pgRNA is stable during the process of blood collection, and therefore, results of pgRNA quantification are reliable.

\section{Introduction}

Chronic hepatitis B virus (HBV) infection is one of the leading causes of morbidity and mortality worldwide (WHO 2017). Serum levels of HBV DNA and HBV surface antigen (HBsAg) are used to evaluate the efficacy of HBV treatment (Terrault et al., 2018). However, there are some limitations of their use in indicating the extent of HBV DNA replication. Recently, HBV pregenomic RNA (pgRNA) quantification is being used as a diagnostic marker to represent HBV cccDNA replication (Liu et al., 2019).

The HBV genome is a $3.2 \mathrm{~kb}$ long, relaxed, circular, and partially double-stranded DNA (Datta et al., 2012). After attaching to and entering the hepatocytes through endocytosis, the viral particles release the relaxed circular DNA (rcDNA) into the nucleus. The rcDNA is repaired to form a covalently closed circular DNA (cccDNA), which becomes the template for transcription 
of viral RNAs (Ganem \& Schneider 2001; Seeger \& Mason 2000). Viral RNAs transcribed from cccDNA consist of pregenomic RNA and subgenomic RNA. Pregenomic RNA is a template for reverse transcription of viral DNA and itself translates into precore, core, and polymerase proteins (Datta et al., 2012). New viral particles are assembled from pregenomic RNA, using viral polymerases, in the cytoplasm. Viral polymerase reverse-transcribes some of the pgRNA back to relaxed circular DNA. This viral particle is either released from hepatocytes through the endoplasmic reticulum and Golgi complex modification or travels back to the nucleus for amplification of the cccDNA pool (Datta et al., 2012; Rehermann \& Nascimbeni 2005). A recent study showed that pgRNA is also encapsidated and released from infected hepatocytes (HBV RNA virion-like particles) (Jansen et al., 2016; Wang et al., 2016).

Circulating serum HBV RNAs are heterogenous, with the major component being pgRNA species, which are localized either in the unenveloped capsid or virion.(Bai et al., 2018) The encapsidated forms are detergent- and ribonuclease-resistant (Shen et al., 2020) and they bind with specific antibodies, forming capsid-antibody complexes (Bai et al., 2018). HBV pgRNA variants are of varying lengths, with some undergoing post-transcriptional splicing at the 5' terminal, while the others are 3' terminally truncated forms (Shen et al., 2020). There is no evidence for the infectivity of these particles (Lu et al., 2017). HBV RNA-virions do not induce a productive infection in vitro, unlike the HBV DNA-virions (Shen et al., 2020).

Pregenomic RNA level is used as an indicator of HBV cccDNA replication. Theoretically, this novel marker would be superior to HBsAg [HBsAg (q)], since the latter can be synthesized from both cccDNA and integrated DNA, resulting in decreased specificity as marker for viral replication (Cornberg et al., 2017). Clinical applications of quantitation of pgRNA levels include monitoring of the treatment efficacy of nucleot(s)ide analogs (NAs) and interferons and determination of when to terminate NA treatment (Huang et al., 2015; Jansen et al., 2016; Tsuge et al., 2013).

In general, RNA is easily degraded by various factors during quantitation, including temperature, storage time, ribonuclease (RNase), or contamination with inhibitors (Sanders et al., 2018). RNA stability was confirmed before the clinical application of various RNA assays, such as those for human immunodeficiency virus (HIV) and hepatitis $\mathrm{C}$ virus (HCV). HIV RNA in plasma can be stored at room temperature $\left(25^{\circ} \mathrm{C}\right)$ and $4{ }^{\circ} \mathrm{C}$ for up to 3 days (Sebire et al., 1998), and $\mathrm{HCV}$ RNA in blood remains stable at $4{ }^{\circ} \mathrm{C}$ for up to 4 days but stability decreases during storage at 23 ${ }^{\circ} \mathrm{C}$ or $37^{\circ} \mathrm{C}$ (de Moreau de Gerbehaye et al., 2002; Krajden et al., 1999).

HBV pgRNA stability under different temperatures and storage durations has not been previously estimated. In addition, stability of the encapsidated form of HBV RNA virion-like particles in blood samples during laboratory processes remains unknown. These estimates are crucial for the use of HBV pgRNA in comparative clinical studies and diagnosis. Thus, we 
111 aimed to instigate the effect of two different temperature conditions and storage durations on the

112 stability of HBV pgRNA.

113

\section{Material and Methods}

115 This study was approved by the Institutional Review Board of Faculty of Medicine,

116 Chulalongkorn University (IRB number 765/61)

117

118 Patient characteristics

119 Adult subjects aged 18 years or older, who had chronic hepatitis B infection were enrolled from

120 The Liver Clinic, King Chulalongkorn Memorial Hospital, Bangkok, Thailand. Patients, selected

121 for the study, showed evidence of active HBV DNA replication, defined by plasma HBV DNA

122 of more than 2,000 IU/mL or quantitative HBsAg of more than 2,000 IU/mL. The exclusion

123 criteria included, (1) coinfection with HIV or HCV and (2) unwillingness to participate in this

124 study. Forty patients met the criteria and were included in this study. All participating patients

125 provided informed written consent.

126

127

\section{Sample collection and processing}

128 Twenty milliliters of blood from the participating patients was collected in EDTA tubes. The

129 plasma was separated at $4^{\circ} \mathrm{C}$ by centrifugation within $2 \mathrm{~h}$ of collection. Plasma samples from

130 each patient were divided into 11 aliquots and stored at $4{ }^{\circ} \mathrm{C}$ and $25^{\circ} \mathrm{C}$ (room temperature) for

131 six different storage durations $(0,2,6,12,24$, and $48 \mathrm{~h})$ and subsequently transferred to $-80^{\circ} \mathrm{C}$

132 for storage.

133

\section{Effect of freezing and thawing of plasma}

135 The effects of multiple freeze-thaw cycles on HBV pgRNA at $-20^{\circ} \mathrm{C}$ and $-80^{\circ} \mathrm{C}$ were assessed.

136 Aliquots of ten plasma samples were stored at $-20^{\circ} \mathrm{C}$ and $-80^{\circ} \mathrm{C}$. A freeze-thaw cycle was

137 defined as freezing at $-20^{\circ} \mathrm{C}$ or $-80{ }^{\circ} \mathrm{C}$ for $22 \mathrm{~h}$ and thawing at room temperature for $2 \mathrm{~h}$. For

138 each sample set, at each temperature, four freeze-thaw cycles were performed. One aliquot was

139 used for quantification after every freeze-thaw cycle.

\section{RNA extraction and quantification}

142 Total RNA from plasma $(200 \mu \mathrm{L})$ was extracted using QIAsymphony DSP Virus/Pathogen Mini

143 Kit (Cat No. 937036; Qiagen Gmbh, Germany) and treated with DNAseI (Cat No. 79256;

144 Qiagen Gmbh) on the QIAsymphony SP/AS instruments, following the manufacturer's

145 instructions. Isolated HBV RNA was reverse transcribed using ImProm-II Reverse Transcriptase

146 (Cat No. A3802; Promega, Madison), with HBV-specific RT primers (5-

147 ATTCTCAGACCGTAGCACACGACACCGAGATTGAGATCTTCTGCGAC-3) as previously

148 described (Wang et al., 2016). To ensure that HBV DNA does not interfere with the RNA

149 estimation, a control PCR, using the RNA samples without reverse transcription as template, was 
150 performed. HBV pgRNA was quantified using the Droplet Digital PCR System (ddPCR) (Wang

151 et al., 2018) (QX200; Bio-Rad Laboratories, Inc., California). The PCR mixture (20 $\mu \mathrm{L})$

152 consisted of $10 \mu \mathrm{L}$ of 2x supermix for probes (Cat No. 1863010; Bio-Rad Laboratories, Inc.,

153 California), $1.8 \mu \mathrm{L}$ of each primer $(10 \mathrm{nM}), 1 \mu \mathrm{L}$ of TaqMan probe $(5 \mathrm{nM}), 2 \mu \mathrm{L}$ of the cDNA

154 template, and $3.4 \mu \mathrm{L}$ of water. The primers and probe used were, forward primer: 5-

155 AYAGACCATCAAATGCCC-3; reverse primer: 5-ATTCTCAGACCGTAGCACACGACAC-3

156 and probe: 5-FAM-CTTATCAACACTTCCGGARACTACTGTTGTTAGAC-BHQ1-3 (Wang

157 et al., 2016). PCR mixture and droplet generation oil $(70 \mu \mathrm{L})$ were added to the DG32 cartridge.

158 The droplets were produced through the automated droplet generator of the QX200 Droplet

159 Digital PCR system (Bio-Rad). Each droplet was transferred to a 96-well PCR plate for

160 amplification using the Mastercycler ${ }^{\circledR}$ Pro Thermal Cyclers (Eppendorf). The following protocol

161 was used: one cycle at $95{ }^{\circ} \mathrm{C}$ for $10 \mathrm{~min}, 40$ cycles at $94{ }^{\circ} \mathrm{C}$ for $30 \mathrm{~s}$ and $56{ }^{\circ} \mathrm{C}$ for $1 \mathrm{~min}$, and one

162 cycle at $98^{\circ} \mathrm{C}$ for $10 \mathrm{~min}$. The concentration of HBV pgRNA was estimated using QuantaSoft ${ }^{\mathrm{TM}}$

163 version 1.7 (Bio-Rad Laboratories, Inc.). The lower limit of detection was determined as 100

164 copies $/ \mathrm{mL}$. The mean lowest quantity (copies $/ \mathrm{mL}$ ) was estimated through serial dilution of

165 specimens until the levels became undetectable in most of the diluted aliquots.

166

167 Statistical analysis

168 Statistical analysis was conducted using Stata 16.0. Results were expressed as mean pgRNA

169 concentration and mean change from baseline for each time duration at each temperature.

170 Changes in pgRNA levels from baseline values were compared using a generalized estimating

171 equation (GEE) adjusting for repeated measurements in each sample. To compare the stability at

172 a particular temperature following freeze-thaw cycles, GEE was used. We calculated the change

173 in ratio per freeze-thaw cycle, relative to 1 cycle at the corresponding temperature, which was

174 used as the reference group. A p-value of 0.05 or less is considered statistically significant.

175 However, a change in pgRNA level greater than $0.5 \log$ copies/mL is considered clinically

176 significant (Pawlotsky 1997).

177

178

\section{Results}

179 From the initial forty plasma samples, HBV pgRNA levels ranged from 3.08 to $8.04 \log _{10}$

180 copies/mL with a mean of $5.58 \log _{10}$ copies/mL (Fig. 1). Changes in HBV pgRNA levels for

181 different durations of storage and temperature are expressed, with mean, standard deviation

182 (SD), minimum (min), median (P50), 25th percentile (P25), 75th percentile (P75), and maximum

183 ( $\max )$ values, in Table 1. Compared to the initial reference sample (time 0 ), using GEE, the mean

184 changes in pgRNA levels were found to be statistically significant. The pgRNA levels of

185 samples stored for $6,12,24$, and $48 \mathrm{~h}$ decreased from the initial values and are presented in Fig.

1862 and Table 2.

187 
188 Since the differences in pgRNA levels for the different storage durations were within $0.5 \log _{10}$ 189 copies $/ \mathrm{mL}$, these changes are not clinically significant. There were also no significant changes in 190 pgRNA levels between the two storage temperatures $\left(-0.01 \log _{10}\right.$ copies $/ \mathrm{mL} ; 95 \% \mathrm{CI}-0.708$ to $1910.689, \mathrm{p}=0.98)$ (Fig. 2).

192

There was no significant difference in the levels of pgRNA in the samples, following the freezethaw cycles (Fig. 3). Four cycles of freezing and thawing did not result in significant ratio changes in HBV pgRNA levels in any of the samples tested $\left(\mathrm{p}=0.45\right.$ and 0.59 for $-20^{\circ} \mathrm{C}$ and $80{ }^{\circ} \mathrm{C}$, respectively) (Table 3 ).

\section{Discussion}

200

201 HBV pgRNA levels are increasingly being used as a biomarker of intrahepatic cccDNA replication, and have been studied for their role in HBV pathogenesis and treatment. However, there exists no standard for collection, processing, and storage to ensure the accuracy and reproducibility of quantification tests (Liu et al., 2019).

Based on our results, we conclude that blood samples collected in EDTA, and processed at $4{ }^{\circ} \mathrm{C}$ within $2 \mathrm{~h}$ of collection can be stored at $4{ }^{\circ} \mathrm{C}$ and $25^{\circ} \mathrm{C}$ for up to $48 \mathrm{~h}$ without significantly affecting pgRNA levels. In addition, there was no significant difference in the levels of HBV pgRNA following four freeze-thaw cycles. The aforementioned time duration for blood collection and processing can be applied to real-world situations, in which the time from blood collection to quantification is within $48 \mathrm{~h}$ before being shipped to a central laboratory for further processing. The two temperature points investigated in our study are frequently used for storage and transport of blood samples. In addition, multiple freeze-thaw cycles at $-20^{\circ} \mathrm{C}$ and $-80{ }^{\circ} \mathrm{C}$ are frequently used in clinical research.

213

For accuracy and consistency of the quantification process, the automated system for RNA extraction used in this study allowed for less human interference and RNase contamination. The co-extracted DNA that remained after DNase reaction was tested using HBV DNA-specific and housekeeping DNA primers. In the 8 selected samples, DNA did not remain after the DNase reaction.

However, there was a slight decrease in the HBV pgRNA level in samples 29 and 33 (Fig. S1, $\mathrm{S} 2$, and Table S1). One explanation for this decrease might stem from an oxidation reaction (Relova et al., 2018). Thus, shorter period of handling before storage and controlled lowtemperature transfer would reduce this variation.

Some of the mean changes in HBV pgRNA levels, from the baseline levels, for storage duration and temperature were found to be significantly different (Table 1). A generalized estimating equation (GEE), adjusting for repeated measurements in each sample, was applied to build a 
228

229

230

231

232

233

234

235

236

237

238

239

240

241

242

243

244

245

246

247

248

249

250

251

252

253

254

255

256

257

258

259

260

261

262

263

264

265

266

267

statistical model for repeated measurements. The GEE findings indicated significant changes in pgRNA levels in samples with a storage duration beyond $6 \mathrm{~h}$ (Table 2). However, these findings were only an illustration of the statistical reliability. In terms of clinical application, these changes are acceptable and not significant, because clinical differences are considered significant only when the change in pgRNA levels is more than $0.5 \log _{10}$ copies/mL (Baleriola et al., 2011; Pawlotsky 1997).

Currently, there is no standard method for serum HBV pgRNA detection (Liu et al., 2019). Digital PCR (dPCR), in addition to its excellent sensitivity and quantification of the target molecule, does not need a standard controlled curve, as those required in real-time or other quantitative PCR assays (qPCR) (Cao et al., 2017). It also sensitive to very low levels of circulating nucleic acids in blood (Kuypers \& Jerome 2017). A study comparing HBV DNA detection using qPCR and APCR showed lower copy number detection and better reproducibility of the dPCR assay, which improves sensitivity and specificity for serum HBV DNA measurements (Tang et al., 2016). In this study, we performed pgRNA quantification by dPCR to ensure that samples with very low titers of HBV pgRNA could be detected.

Species and forms of serum HBV RNA have not yet been clearly identified. Wang et al. reported that HBV RNA detected in the supernatant is pgRNA contained in the enveloped particles (Wang et al., 2016). However, more evidence is needed to confirm this (Liu et al., 2019). In addition, serum HBV RNA is heterogeneous, comprising an intact genome length of 3.5-kb along with spliced and polyA-free pgRNA, and varies depending on the stage of chronic HBV infection, medication administered, and detection methods (Hacker et al., 2004; Liu et al., 2019; Shen et al., 2020; Wang et al., 2016). We used an HBV-specific primer pair as described by Wang et al., which selectively amplified specific pgRNA species (Wang et al., 2016). The primers target a sequence upstream of DR2; the PCR amplicon is located between the 3' splicing site and the RT primer site. This yields a more specific amplicon, with better coverage of the spliced and 3' truncated forms, which are the predominant species of serum HBV pgRNA (Shen et al., 2020).

The stability of pgRNA observed in this study might reflect the nature of the HBV RNA itself, and indicates encapsidation of the internal RNA, thus improving its resistance to the environment.

This study had several limitations. In future investigations, only the robust reproduction of specimen handling, processing, and storage techniques, described in our study, can result in pgRNA stabilities similar to that reported in this study. Other storage times and temperatures cannot be applied. Second, we measured only pgRNA specific to the HBV pgRNA-specific primer. There are no data on variation in the levels of other HBV RNA species. Our method, however, can be applied as a future reference. Finally, this stability was observed in patients under the current approved HBV treatment. Patients recruited in this study were either NA naïve 
268 or under NA treatment at the time of the study. NA treatment does not interfere with the

269 encapsidation of HBV virions. However, some novel anti-HBV drugs that target pgRNA, such as

270 (Z)-2-(allylamino)-4-amino-N'-cyanothiazole-5-carboximidamide (AACC), inhibit pgRNA and

271 polymerase action, resulting in capsid assembly inhibition and encapsidated pgRNA reduction

272 (Jo et al., 2020). There is still a lack of data on HBV pgRNA levels in patients using these new

273 drugs.

274

275 Conclusions

276 We have demonstrated the stability of the plasma level of HBV pgRNA at $4{ }^{\circ} \mathrm{C}$ and room

277 temperature for up to $48 \mathrm{~h}$ and following multiple freeze-thaw cycles before it is quantified. Our

278 results confirmed the stability of pgRNA using the established strategy of blood collection and

279 storage, and thus, quantitation of pgRNA is reliable.

280

281 Acknowledgements

282 We would like to thank Professor Stephen Kerr, BPharm (Hons), MIPH, PhD, Director,

283 Biostatistics Excellence Center, Faculty of Medicine, Chulalongkorn University, and

284 Biostatistics at HIV-NAT for data analysis.

285

286

287

288

289

290

291

292

293

294

295

296

297

298

299

300

301

302

303

Peer) reviewing PDF | (2020:10:53681:1:1:NEW 10 Mar 2021) 


\section{References}

307

308

309

310

311

312

313

314

315

316

317

318

319

320

321

322

323

324

325

326

327

328

329

330

331

332

333

334

335

336

337

338

339

340

341

342

343

344

345

346

347

348

Bai L, Zhang X, Kozlowski M, Li W, Wu M, Liu J, Chen L, Zhang J, Huang Y, and Yuan Z. 2018. Extracellular Hepatitis B Virus RNAs Are Heterogeneous in Length and Circulate as CapsidAntibody Complexes in Addition to Virions in Chronic Hepatitis B Patients. Journal of Virology 92. 10.1128/jvi.00798-18

Baleriola C, Johal H, Jacka B, Chaverot S, Bowden S, Lacey S, and Rawlinson W. 2011. Stability of hepatitis $\mathrm{C}$ virus, $\mathrm{HIV}$, and hepatitis $\mathrm{B}$ virus nucleic acids in plasma samples after long-term storage at $-20^{\circ} \mathrm{C}$ and $-70^{\circ} \mathrm{C}$. Journal of Clinical Microbiology 49:3163-3167. 10.1128/JCM.02447-10

Cao L, Cui X, Hu J, Li Z, Choi JR, Yang Q, Lin M, Ying Hui L, and Xu F. 2017. Advances in digital polymerase chain reaction (dPCR) and its emerging biomedical applications. Biosensors and Bioelectronics 90:459-474.

Cornberg M, Wong VW, Locarnini S, Brunetto M, Janssen HLA, and Chan HL. 2017. The role of quantitative hepatitis B surface antigen revisited. Journal of Hepatology 66:398-411. 10.1016/j.jhep.2016.08.009

Datta S, Chatterjee S, Veer V, and Chakravarty R. 2012. Molecular biology of the hepatitis B virus for clinicians. Journal of Clinical and Experimental Hepatology 2:353-365. 10.1016/j.jceh.2012.10.003

de Moreau de Gerbehaye AI, Bodeus M, Robert A, Horsmans Y, and Goubau P. 2002. Stable hepatitis C virus RNA detection by RT-PCR during four days storage. BMC Infectious Diseases 2:22.

Ganem D, and Schneider R. 2001. Hepadnaviridae:the viruses and their replication. In: Knipe D, and Howley P, eds. Fields Virology. Philadelphia: Lippincott Williams \& Wilkins, 2923-2969.

Hacker HJ, Zhang W, Tokus M, Bock T, and Schroder CH. 2004. Patterns of circulating hepatitis B virus serum nucleic acids during lamivudine therapy. Annals of the New York Academy of Sciences 1022:271-281. 10.1196/annals. 1318.042

Huang YW, Takahashi S, Tsuge M, Chen CL, Wang TC, Abe H, Hu JT, Chen DS, Yang SS, Chayama K, and Kao JH. 2015. On-treatment low serum HBV RNA level predicts initial virological response in chronic hepatitis B patients receiving nucleoside analogue therapy. Antiviral Therapy 20:369375. 10.3851/imp2777

Jansen L, Kootstra NA, van Dort KA, Takkenberg RB, Reesink HW, and Zaaijer HL. 2016. Hepatitis B virus pregenomic RNA is present in virions in plasma and Is associated with a response to pegylated interferon alfa-2a and nucleos(t)ide analogues. Journal of Infectious Diseases 213:224232. 10.1093/infdis/jiv397

Jo E, Ryu D-K, König A, Park S, Cho Y, Park S-H, Kim T-H, Yoon SK, Ryu W-S, Cechetto J, and Windisch MP. 2020. Identification and characterization of a novel hepatitis B virus pregenomic RNA encapsidation inhibitor. Antiviral Research 175:104709.

Krajden M, Minor JM, Zhao J, Rifkin O, and Comanor L. 1999. Assessment of hepatitis C virus RNA stability in serum by the quantiplex branched DNA assay. Journal of Clinical Virology 14:137143.

Kuypers J, and Jerome KR. 2017. Applications of digital PCR for clinical Microbiology. Journal of Clinical Microbiology 55:1621-1628. 10.1128/jcm.00211-17

Liu S, Zhou B, Valdes JD, Sun J, and Guo H. 2019. Serum hepatitis B virus RNA: A new potential biomarker for chronic hepatitis B virus infection. Hepatology 69:1816-1827. 10.1002/hep.30325

Peer) reviewing PDF | (2020:10:53681:1:1:NEW 10 Mar 2021) 
349

350

351

352

353

354

355

356

357

358

359

360

361

362

363

364

365

366

367

368

369

370

371

372

373

374

375

376

377

378

379

380

381

382

383

384

385

386

387

388

389

390
Lu F, Wang J, Chen X, Xu D, and Xia N. 2017. Potential use of serum HBV RNA in antiviral therapy for chronic hepatitis B in the era of nucleos(t)ide analogs. Frontiers of Medicine 11:502-508. $10.1007 / \mathrm{s} 11684-017-0590-\mathrm{z}$

Pawlotsky JM. 1997. Measuring hepatitis C viremia in clinical samples: can we trust the assays? Hepatology 26:1-4. 10.1002/hep.510260131

Rehermann B, and Nascimbeni M. 2005. Immunology of hepatitis B virus and hepatitis C virus infection. Nature Reviews: Immunology 5:215-229. 10.1038/nri1573

Relova D, Rios L, Acevedo AM, Coronado L, Perera CL, and Pérez LJ. 2018. Impact of RNA degradation on viral diagnosis: An understated but essential step for the successful establishment of a diagnosis network. Veterinary Sciences 5:19. 10.3390/vetsci5010019

Sanders R, Bustin S, Huggett J, and Mason D. 2018. Improving the standardization of mRNA measurement by RT-qPCR. Biomolecular detection and quantification 15:13-17. 10.1016/j.bdq.2018.03.001

Sebire K, McGavin K, Land S, Middleton T, and Birch C. 1998. Stability of human immunodeficiency virus RNA in blood specimens as measured by a commercial PCR-based assay. Journal of Clinical Microbiology 36:493-498.

Seeger C, and Mason WS. 2000. Hepatitis B virus biology. Microbiology and Molecular Biology Reviews 64:51-68.

Shen S, Xie Z, Cai D, Yu X, Zhang H, Kim ES, Zhou B, Hou J, Zhang X, Huang Q, Sun J, and Guo H. 2020. Biogenesis and molecular characteristics of serum hepatitis B virus RNA. PLoS Pathogens 16:e1008945. 10.1371/journal.ppat.1008945

Tang H, Cai Q, Li H, and Hu P. 2016. Comparison of droplet digital PCR to real-time PCR for quantification of hepatitis B virus DNA. Bioscience, Biotechnology, and Biochemistry:1-6. 10.1080/09168451.2016.1196576

Terrault NA, Lok ASF, McMahon BJ, Chang KM, Hwang JP, Jonas MM, Brown RS, Jr., Bzowej NH, and Wong JB. 2018. Update on prevention, diagnosis, and treatment of chronic hepatitis B: AASLD 2018 hepatitis B guidance. Hepatology 67:1560-1599. 10.1002/hep.29800

Tsuge M, Murakami E, Imamura M, Abe H, Miki D, Hiraga N, Takahashi S, Ochi H, Nelson Hayes C, Ginba H, Matsuyama K, Kawakami H, and Chayama K. 2013. Serum HBV RNA and HBeAg are useful markers for the safe discontinuation of nucleotide analogue treatments in chronic hepatitis B patients. Journal of Gastroenterology 48:1188-1204. 10.1007/s00535-012-0737-2

Wang J, Shen T, Huang X, Kumar GR, Chen X, Zeng Z, Zhang R, Chen R, Li T, Zhang T, Yuan Q, Li PC, Huang Q, Colonno R, Jia J, Hou J, McCrae MA, Gao Z, Ren H, Xia N, Zhuang H, and Lu F. 2016. Serum hepatitis B virus RNA is encapsidated pregenome RNA that may be associated with persistence of viral infection and rebound. Journal of Hepatology 65:700-710. 10.1016/j.jhep.2016.05.029

Wang J, Yu Y, Li G, Shen C, Meng Z, Zheng J, Jia Y, Chen S, Zhang X, Zhu M, Zheng J, Song Z, Wu J, Shao L, Qian P, Mao X, Wang X, Huang Y, Zhao C, Zhang J, Qiu C, and Zhang W. 2018.

Relationship between serum HBV-RNA levels and intrahepatic viral as well as histologic activity markers in entecavir-treated patients. Journal of Hepatology 68:16-24.

WHO. 2017. Global Hepatitis Report 2017. Geneva: World Health Organization. 
Figure 1

HBV pgRNA degradation over time and temperature.

The mean (+/- 1SE) of HBV pgRNA level in plasma stored at either 4 or $25^{\circ} \mathrm{C}$. HBV pgRNA loads, expressed in $\log _{10}$ copies/mL, were measured at 2, 6, 12, 24 and $48 \mathrm{~h}$. Triangles indicate $4{ }^{\circ} \mathrm{C}$ storage and circles indicate $25^{\circ} \mathrm{C}$ storage.

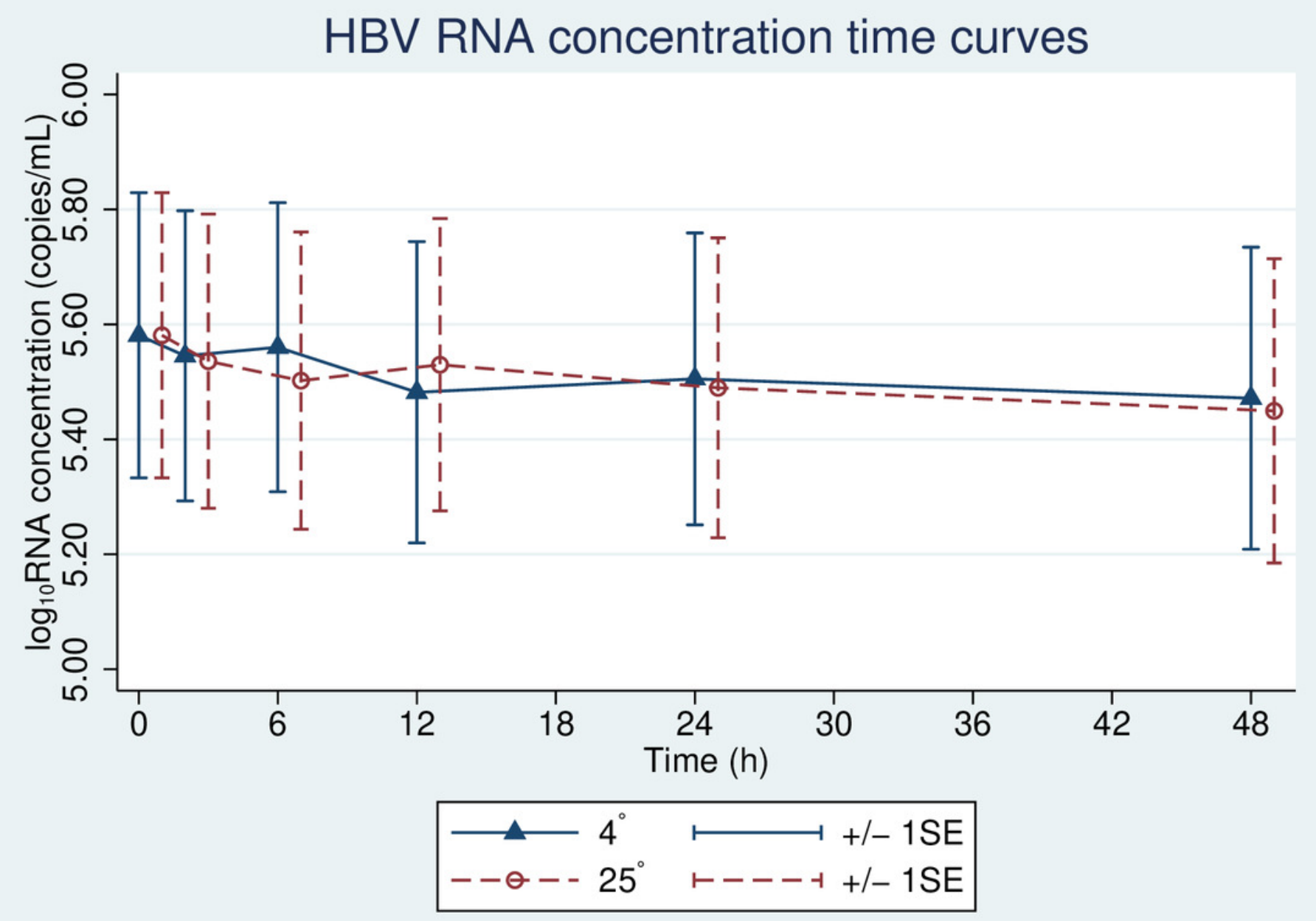


Figure 2

Changes in HBV pgRNA level from baseline.

The mean $(+/-1 \mathrm{SE})$ of HBV pgRNA level change from baseline (time $=0$ ) in plasma stored at either 4 or $25^{\circ} \mathrm{C}$. HBV pgRNA loads, expressed in $\log _{10}$ copies $/ \mathrm{mL}$, were measured at $2,6,12$, 24 and $48 \mathrm{~h}$. Circles indicate $4{ }^{\circ} \mathrm{C}$ storage and squares indicate $25^{\circ} \mathrm{C}$ storage.

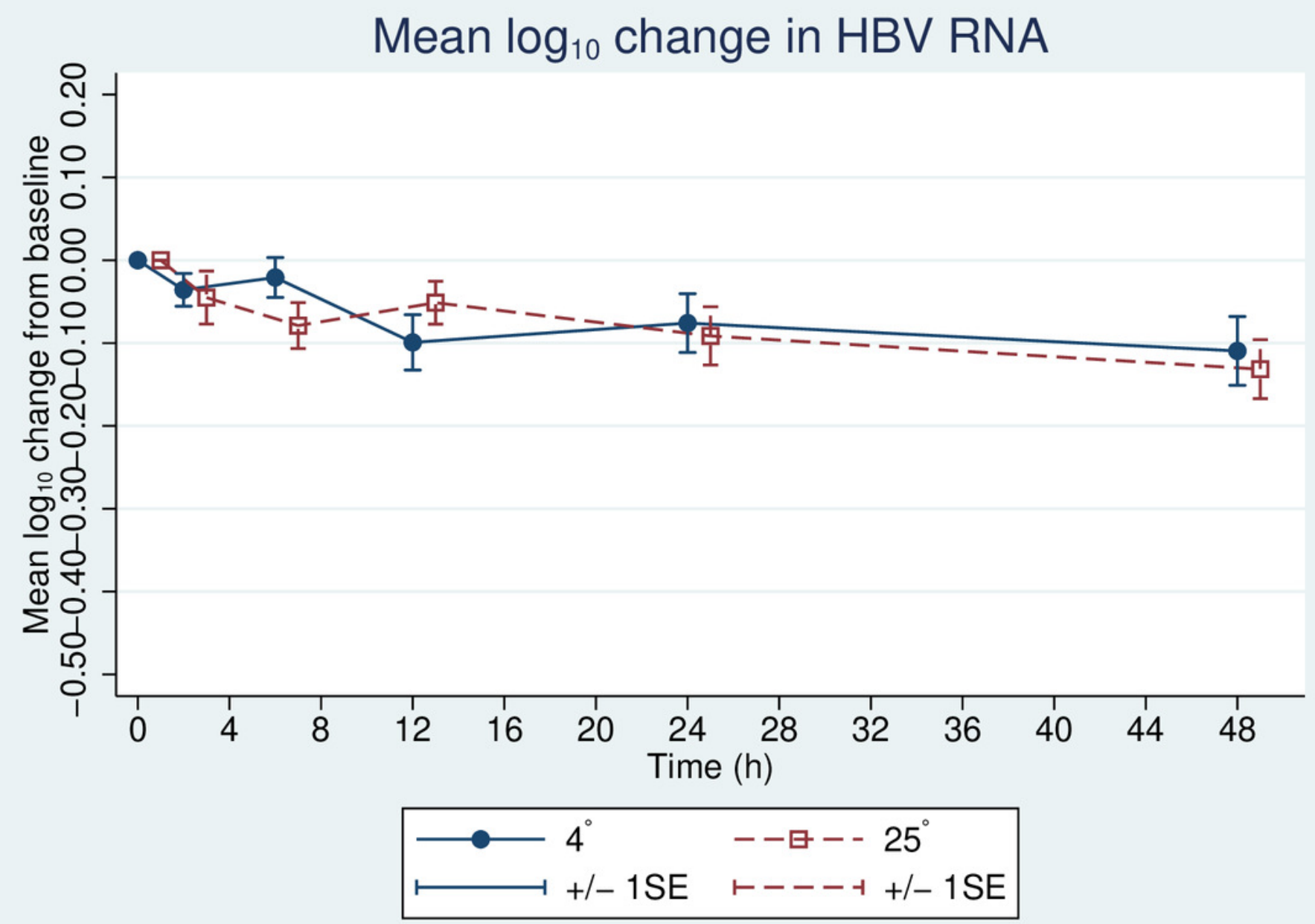


Figure 3

HBV pgRNA concentration over multiple freeze-thaw cycles at $-20^{\circ} \mathrm{C}$ and $-80{ }^{\circ} \mathrm{C}$.

The mean (+/- 1SE) of HBV pgRNA levels, expressed as $\log _{10}$ copies $/ \mathrm{mL}$, were measured for up to four freeze-thaw cycles. Triangles and circles indicate storage at $-80^{\circ} \mathrm{C}$ and $-20{ }^{\circ} \mathrm{C}$, respectively.

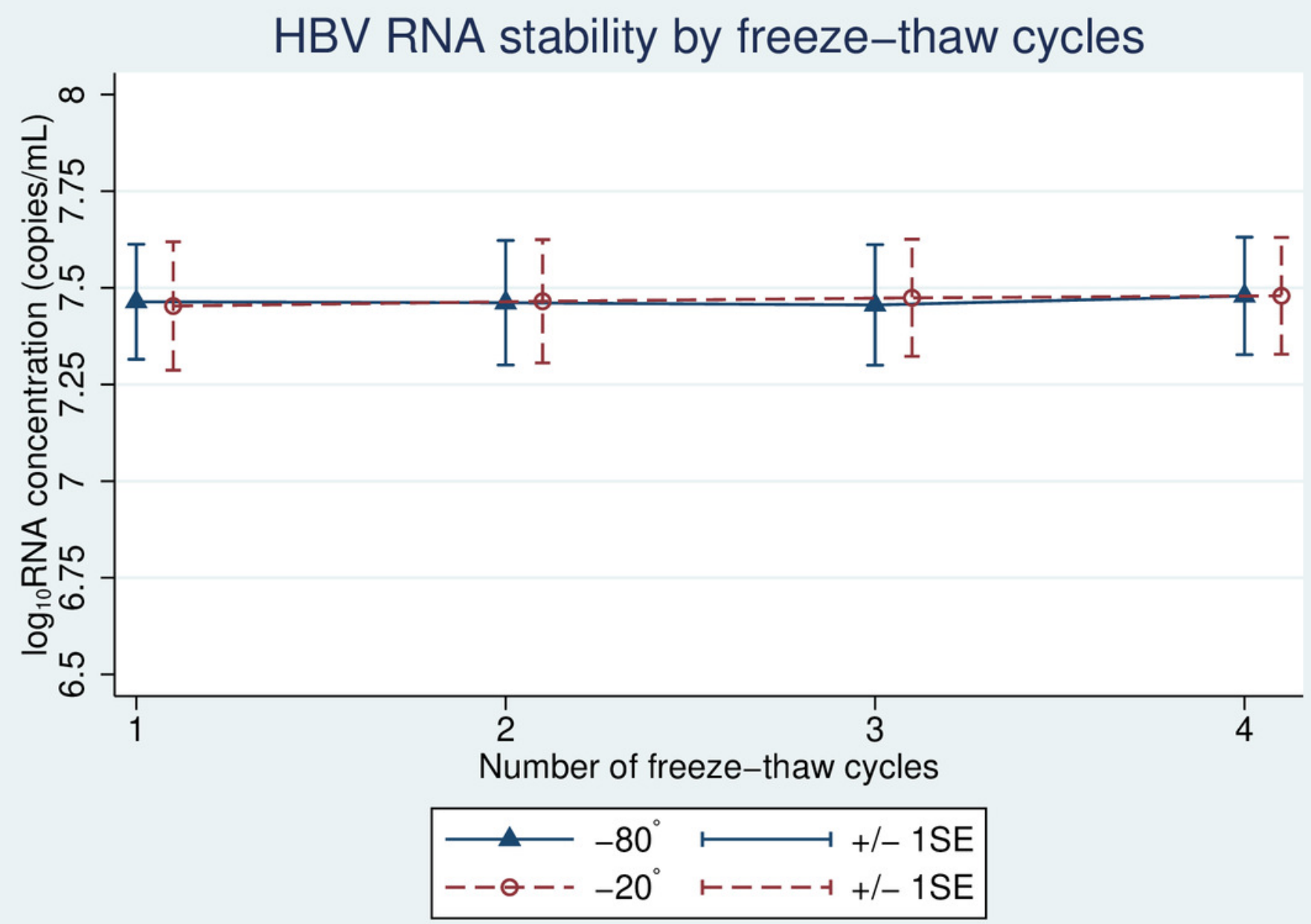




\section{Table $\mathbf{1}$ (on next page)}

Changes in HBV pgRNA for each storage duration and at two different temperatures, (A) $4^{\circ} \mathrm{C}$ and (B) room temperature $\left(25^{\circ} \mathrm{C}\right)$ 


\begin{tabular}{|c|c|c|c|c|c|c|c|c|c|}
\hline Time $(\mathrm{h})$ & $\mathrm{N}$ & mean & $\mathrm{SD}$ & $\min$ & $\mathrm{P} 25$ & $\mathrm{P} 50$ & $\mathrm{P} 75$ & $\max$ & $\mathrm{p}^{*}$ \\
\hline 0 & 40 & 0 & 0 & 0 & 0 & 0 & 0 & 0 & - \\
\hline 2 & 40 & -0.04 & 0.13 & -0.45 & -0.1 & -0.02 & 0.05 & 0.16 & 0.29 \\
\hline 6 & 40 & -0.02 & 0.15 & -0.52 & -0.09 & 0.00 & 0.06 & 0.35 & 0.54 \\
\hline 12 & 40 & -0.1 & 0.21 & -0.95 & -0.17 & -0.04 & 0.03 & 0.22 & 0.004 \\
\hline 24 & 40 & -0.08 & 0.22 & -0.83 & -0.18 & -0.03 & 0.05 & 0.37 & 0.03 \\
\hline 48 & 40 & -0.11 & 0.26 & -1.38 & -0.2 & -0.06 & 0.04 & 0.25 & 0.001 \\
\hline
\end{tabular}

\begin{tabular}{|c|c|c|c|c|c|c|c|c|c|}
\hline Time (h) & $\mathrm{N}$ & mean & $\mathrm{SD}$ & $\min$ & $\mathrm{P} 25$ & $\mathrm{P} 50$ & $\mathrm{P} 75$ & $\max$ & $\mathrm{p}^{*}$ \\
\hline 0 & 40 & 0 & 0 & 0 & 0 & 0 & 0 & 0 & - \\
\hline 2 & 40 & -0.05 & 0.2 & -0.71 & -0.12 & -0.01 & 0.08 & 0.32 & 0.13 \\
\hline 6 & 40 & -0.08 & 0.17 & -0.51 & -0.13 & -0.07 & 0.04 & 0.18 & 0.009 \\
\hline 12 & 40 & -0.05 & 0.16 & -0.37 & -0.16 & -0.04 & 0.07 & 0.39 & 0.09 \\
\hline 24 & 40 & -0.09 & 0.22 & -1.08 & -0.13 & -0.07 & 0.05 & 0.22 & 0.002 \\
\hline 48 & 40 & -0.13 & 0.22 & -0.95 & -0.18 & -0.08 & 0.00 & 0.16 & $<0.001$ \\
\hline
\end{tabular}

* comparison of mean levels for each storage duration with initial levels $(\mathrm{t}=0)$ HBV pgRNA loads were expressed in $\log _{10}$ copies $/ \mathrm{mL}$.

h, hours; SD, standard deviation; min, minimum; P25, 25th percentile; P50, median; P75, 75th percentile; max, maximum 


\section{Table 2 (on next page)}

Generalized estimating equation (GEE) results comparing the differences of mean baseline pgRNA level and mean pgRNA level for each storage duration 
1

\begin{tabular}{|c|c|c|}
\hline Time (h) & Coefficient $(95 \% \mathrm{CI})$ & $\mathrm{p}$ \\
\hline 0 & 0 (Reference) & - \\
\hline 2 & $-0.04(-0.085$ to 0.004$)$ & 0.08 \\
\hline 6 & $-0.05(-0.095$ to -0.005$)$ & 0.03 \\
\hline 12 & $-0.075(-0.12$ to -0.03$)$ & 0.001 \\
\hline 24 & $-0.084(-0.13$ to -0.039$)$ & $<0.001$ \\
\hline 48 & $-0.120(-0.17$ to -0.076$)$ & $<0.001$ \\
\hline
\end{tabular}

2 h, hours; CI, confidence interval.

3

4 


\section{Table 3(on next page)}

Generalized estimating equation (GEE) results comparing the ratio changes per freezethaw cycle, relative to 1 cycle as the reference group. 
1

\begin{tabular}{|c|c|c|}
\hline Temperature and Cycle number & Ratio change $(95 \% \mathrm{CI})$ & $\mathrm{P}$ \\
\hline$-80^{\circ} \mathrm{C}$ & & 0.59 \\
\hline 1 & 1 (ref) & \\
\hline 2 & $1(0.96-1.03)$ & \\
\hline 3 & $0.99(0.96-1.03)$ & \\
\hline 4 & $1.02(0.98-1.05)$ & \\
\hline$-20^{\circ} \mathrm{C}$ & & 0.45 \\
\hline 1 & 1 (ref) & \\
\hline 2 & $1.01(0.98-1.05)$ & \\
\hline 3 & $1.02(0.99-1.06)$ & \\
\hline 4 & $1.03(0.99-1.06)$ & \\
\hline
\end{tabular}

2 